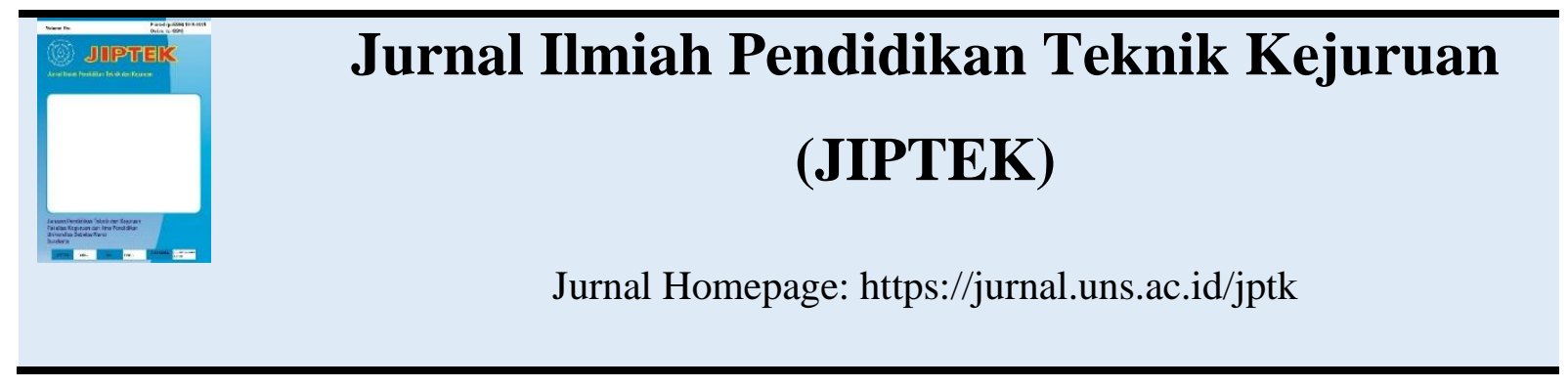

\title{
PENGEMBANGAN SENSOR PENCEGAH TERORIS PADA MODEL BANGUNAN 3D SEBAGAI MEDIA PEMBELAJARAN
}

\author{
Alhara Yuwanda ${ }^{1}$, Ribut Nawang Sari ${ }^{2}$, Prasetyo ${ }^{3}$, Dwi Priyokusumo ${ }^{4}$ \\ 1,2,3,4Jurusan Teknik Elektro, Sekolah Tinggi Teknologi Jakarta \\ Email: alhara@sttj.ac.id
}

\begin{abstract}
ABSTRAK:
Penjelasan materi ajar yang tidak bervariasi dapat menjadi penyebab tidak tercapainya tujuan pembelajaran. Model anatomi bangunan 3D adalah salah satu media pembelajaran yang mampu meningkat pemahaman tentang ilmu elektonika. Penelitian dilakukan dengan metode research and development $(\mathrm{RnD})$. Perancangan desain yang dilakukan penyesesuaian pembelajaran konstruksi bangunan dengan perancangan model anatomi 3D yang relevan dengan sensor pengaman. Uji hasil sensor keamanan pada prototype mencatat nilai posisi, kelembapan, temperature, heat index, logam detector berfungsi dengan baik $100 \%$. Selanjutnya dilakukan uji coba prototype sebagai media pembelajaran dan diuji dengan instrument dengan kuisioner. Berdasarkan uji terhadap 10 responden instrumen ini sudah valid dan realibel. Data penelitian menunjukan bahwa, sebelum dilakukan pembelajaran menggunakan media Sensor keamanan objek, nilai rata-rata peserta didik adalah 52,62. Pembelajaran menggunakan media berupa Sensor keamanan objek dapat meningkatkan prestasi peserta didik sebesar 82,514\%. Prototipe aplikasi ini diharapkan mampu memberikan meningkatkan kepemahaman terhadap siswa tentang sensor elektronika.
\end{abstract}

Kata Kunci: Sensor, prototype, media pembelajaran

\begin{abstract}
Explanation of teaching material that does not vary can be the cause of not achieving learning objectives. The 3D building anatomy model is one of the learning media that is able to increase the understanding of electronics. The research was conducted using the research and development (RnD) method. The design of the design is done by adjusting building construction learning by designing $3 D$ anatomical models that are relevant to safety sensors. Test the results of security sensors on the prototype record the value of position, humidity, temperature, heat index, metal detector to function properly $100 \%$. Furthermore, a prototype trial was conducted as a learning medium and tested with instruments with questionnaires. Based on the test of 10 respondents this instrument is valid and reliable. The research data shows that, before learning using media object security sensors, the average value of students is 52.62. Learning using media in the form of object security sensors can increase student achievement by $82.514 \%$. This application prototype is expected to be able to provide an increased understanding of students about electronic sensors.
\end{abstract}

Keyword: Digester, Sensor, Methane 


\section{PENDAHULUAN}

Media elektronika sebagai akibat dari perkembangan teknologi, merupakan hal menarik bagi para peserta didik. Manfaat aktivitas dalam pembelajaran yang disebabkan oleh kemajuan ilmu dan teknologi adalah agar siswa dapat mencari sendiri dan langsung mengalami proses belajar (Asyhar, 2011). Belajar yang dimaksud berupa pembelajaran yang dilaksanakan secara realistik dan kongkrit, sehingga mengembangkan pemahaman dan berpikir kritis serta menghindari terjadinya verbalisme yang terus-menerus. Penyampaian materi ajar yang tidak bervariasi dapat menjadi penyebab tidak tercapainya tujuan pembelajaran yang diinginkan. Dengan adanya variasi dalam pembelajaran diharapkan siswa dapat berbuat sendiri yang pada akhirnya akan menjadi kreatif dan inovatif.

Media pembelajaran prototype sensor keamanan anti deteksi pencegah teroris adalah salah satu media pendidikan berupa pelatihan yang dirancang dan dibuat untuk keperluan dalam pembelajaran mata pelajaran perbaikan dan perawatan peralatan elektronika (Adrianto, 2011). Diperlukan pembaharuan dan inovasi dalam pembuatan model anatomi 3D. salah satunya dengan penambahan sistem kemanan (Petruzella, 2001). Pendidikan tentang sistem dan sensor keamanan yang dihubungkan mikrokontroller merupakan salah satu alat bantu belajar di pendidikan elektronika. Ketika keamanan kehilangan salah satu dari signal tersebut, maka dapat dicari dari daftar benda pada Base Unit dan memilih pengunjung yang hilang tersebut. Setelah itu Base Unit akan mengirimkan sinyal RF ke perangkat receiver benda yang ada dalam daftar benda di Base Unit. Remote Unit yang sesuai dengan kode dari Base Unit akan merespons dengan mengeluarkan suara yang dapat didengar dan LED indikator menyala sehingga pengguna dapat menemukan orang yang hilang tersebut. Selain itu mikro kontroler juga lengkapi beberapa sensor seperti sensor logam dan sensor ledakan sehingga ketika melakukan kejahatan teroris dapat dideteksi lebih dini. Dalam penelitian ini akan pengembangan dan uji efektifitas penggunaan mikrokontroler dalam simulasi pencegahan terorisme, pada pengembangan model anatomi bangunan 3D sebagai media pembelajaran (Muis, 2013).

\section{MATERIAL DAN METODOLOGI PENELITIAN}

\section{Alat dan Bahan}

Resin, Cat, Model 3D Rumah, mikrokontroller ATmega8535, LCD, modulator FSK, pemancar FM, Remote Unit, Port B, Port C, Port D, Modul Keypad, Audio Amplifier, Transistor, Oscillator, Power Amplifier, Sensor Ledakan, Kamera CCTV.

\section{Desain Bangunan}

Perancangan desain yang dilakukan berupa perancangan Anatomi Bangunan 3D sesuai pembelajaran konstruksi bangunan dengan perancangan model model anatomi 3D yang relevan,suara bantu informatif, dan suara bantu informatif untuk mempermudah proses pembelajaran. Sebelum melakukan pengujian alat, kami melakukan berbagai perancangan dalam pembuatan prototipe ini karena dalam hal ini yang menjadi pertimbangan dalam 
melakukan suatu pengujian.

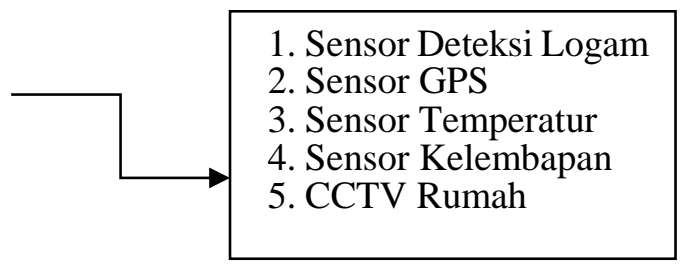

Gambar 1. Model Bangunan dan Rencana Penambahan Sensor Pada Bangunan Pada Bagian Dalam

\section{Rancang Bangun Sensor}

Dilakukan uji coba produk sensor yang dipasangkan pada anatomi bangunan 3D. Apabila dalam penggunaan alat tersebut ditemukan kekurangan, maka produk media pelu diadakannya revisi. Revisi ini berupa pengembangan lanjutan produk agar dalam penggunaannya dapat dilakukan dengan mudah oleh para guru dan siswa.
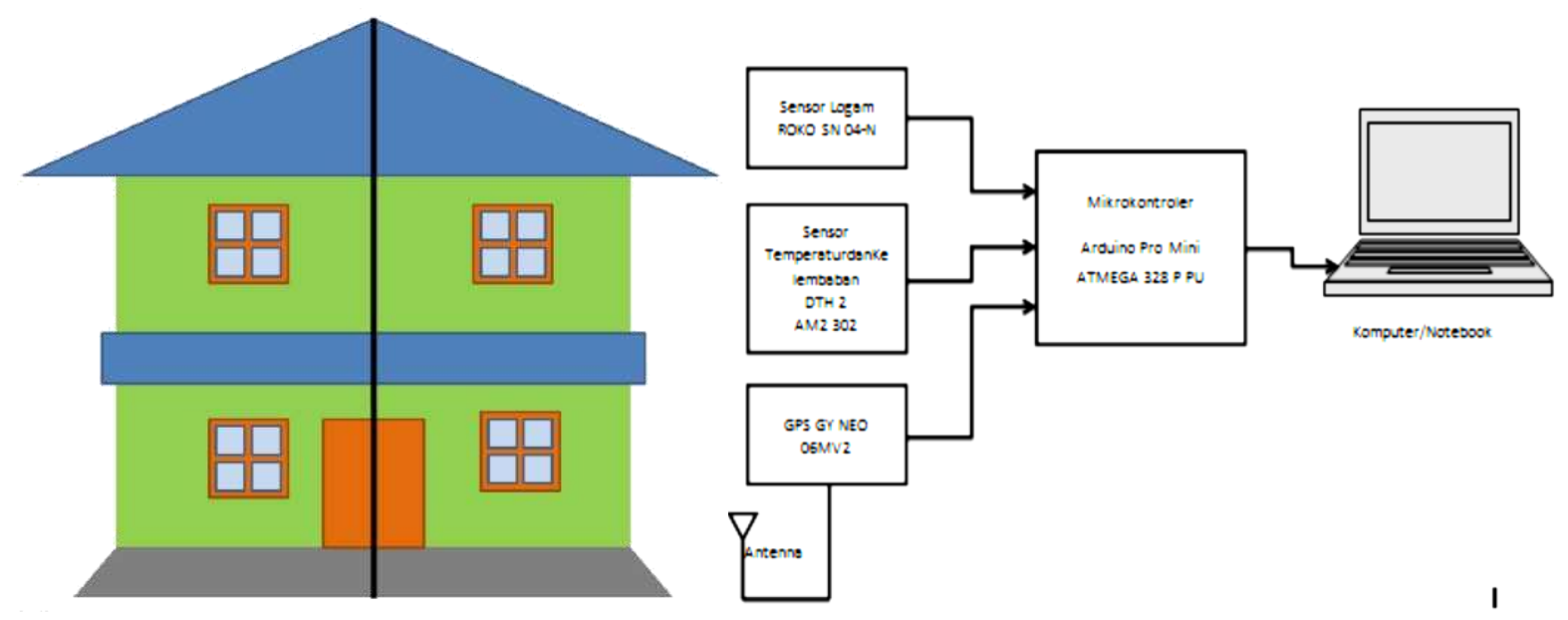

Gambar 2. Desain Sensor Pengaman Pada Rumah

\section{Teknik Pengumpulan Data}

Penelitian ini diawali dengan melakukan analisis kebutuhan dengan menggunakan kuesioner analisis kebutuhan guru dan siswa. Proses penelitian dilanjutkan pada uji kelayakan oleh tim ahli dari segi materi dan media dengan menggunakan kuesioner uji ahli materi dan media. Produk yang dihasilkan di uji coba kepada siswa dalam kelompok kecil dan kelompok besar dengan menggunakan kuesioner siswa. Instrumen tentang media pembelajaran ini terdiri dari 3 aspek, yaitu: Aspek kemanfaatan, Aspek rekayasa perangkat keras dan rekayasa perangkat lunak, Aspek komunikasi visual. Aspek kemanfaatan, yaitu aspek yang berfungsi untuk menilai sensor rumah deteksi sebagai media pembelajaran ditinjau dari tingkat kemanfaatan prototype tersebut terhadap kebutuhan pembelajaran. Aspek rekayasa perangkat keras dan rekayasa perangkat lunak, yaitu aspek yang berfungsi untuk menilai prototype pendeteksi objek ditinjau dari bentuk/rekayasa secara hardware ataupun software prototype sebagai media pembelajaran. Aspek komunikasi visual, yaitu aspek yang berfungsi untuk menilai prototype sensor rumah deteksi objek ditinjau dari tampilan sensor rumah sebagai media pembelajaran yang unik dan menarik pada proses pembelajaran (Irhamna \& Widyo, 2009).

\section{Analisis Instrumen}

Dilakukan uji validitas adalah suatu 
ukuran yang menunjukkan tingkat-tingkat kevalidan atau kesahihan suatu instrumen (Hobri, 2009). Penelitian ini menggunakan instrumen angket/ kuosioner dan instrumen tes. Penelitian ini, data penelitian menggunakan instrumen non-tes akan dibandingkan dengan suatu kriteria yang telah ada, sehingga instrument non-tes memerlukan uji validitas empiris. Data penelitian menggunakan instrumen tes hanya dideskriptifkan dan tidak dibandingkan dengan suatu kriteria tertentu, sehingga instrumen tes tidak memerlukan uji validitas empiris. Analisis data dilakukan dengan cara korelasi product moment dengan angka kasar sebagai berikut:

$$
\begin{aligned}
& r_{x y} \\
& =\frac{N \sum x y-\left(\sum x\right)\left(\sum y\right)}{\sqrt{\left(N \sum x^{2}-\left(\sum x^{2}\right)\right)\left(N \sum y^{2}-\left(\sum y^{2}\right)\right)}}
\end{aligned}
$$

Keterangan : $\operatorname{rxy}=$ koefisien korelasi; $\mathrm{N}=$ Jumlah responden uji coba; $\mathrm{X}=$ Skor tiap item; $\mathrm{Y}=$ Skor seluruh item uji coba

\section{Analisis Data Kelayakan}

Data hasil penelitian ini adalah berupa tanggapan dari 10 peserta didik terhadap kualitas produk yang dikembangkan ditinjau dari aspek relevansi materi, aspek teknis media pembelajaran, aspek kemanfaatan, aspek rekayasa perangkat keras dan perangkat lunak, aspek komunikasi visual. Jenis data penelitian ini adalah data ordinal, untuk membuat kriteria pencapaian data ordinal yang ada dirubah ke bentuk interval. Pada instrumen angket digunakan 4 (empat) pilihan jawaban, yaitu: sangat layak (4) layak, (3) kurang layak (2) dan tidak layak (1). Empat pilihan jawaban di atas digunakan untuk menentukan adanya gradasi yang akan dirubah ke bentuk interval.

\section{HASIL DAN PEMBAHASAN}

Telah dilakukan penelitian yang dilakukan terdiri dari rangkaian kegiatan yang tersusun dan beberapa rencana. Studi literatur dan diskusi yang dilakukan dengan menelaah teori-teori yang berhubungan dengan mikrokontroller, sensor, GPS, dan karakteristik sensor logam.

\section{Hasil Uji Sensor Keamanan}

Hasil yang dicapai pada penelitian ini adalah berupa purwa rupa simulator sensor pendeteksi konverter data panas, logam, dan lokasi berbasis desktop menggunakan gelombang radio dengan mikrokontroler arduino, sebagai berikut:

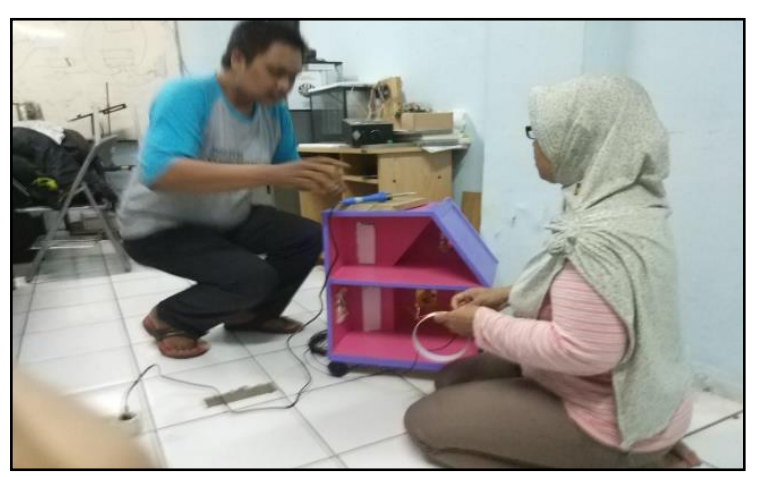

Gambar 3. Prototype Rumah dengan Detektor Keamanan 
Tabel 1. Hasil Pengujian Sensor Deteksi Keamanan

\begin{tabular}{lllllll}
\hline Data & \multicolumn{5}{c}{ Pintu } & Keberhasilan \\
\cline { 2 - 6 } & $\mathbf{1}$ & $\mathbf{2}$ & $\mathbf{3}$ & $\mathbf{4}$ & $\mathbf{5}$ & \\
\hline Latitude & -6.2704057 & -6.2704057 & -6.2704057 & -6.2704057 & -6.2704057 & $100 \%$ \\
\hline Longitude & 106.92 & 106.92 & 106.92 & 106.92 & 106.92 & $100 \%$ \\
\hline Altitude & 330 & 330 & 330 & 330 & 330 & $100 \%$ \\
\hline Humidity & $55.00 \%$ & $55.00 \%$ & $55.00 \%$ & $55.00 \%$ & $55.00 \%$ & $100 \%$ \\
\hline Temperatur & $24.00{ }^{\circ} \mathrm{C}$ & $24.00{ }^{\circ} \mathrm{C}$ & $24.00{ }^{\circ} \mathrm{C}$ & $24.00{ }^{\circ} \mathrm{C}$ & $24.00{ }^{\circ} \mathrm{C}$ & $100 \%$ \\
e & & & & & & \\
\hline Heat index & $23.89^{\circ} \mathrm{C}$ & $23.89^{\circ} \mathrm{C}$ & $23.89^{\circ} \mathrm{C}$ & $23.89^{\circ} \mathrm{C}$ & $23.89^{\circ} \mathrm{C}$ & $100 \%$ \\
\hline $\begin{array}{l}\text { Deteksi } \\
\text { Logam }\end{array}$ & Berhasil & Berhasil & Berhasil & Berhasil & Berhasil & $100 \%$ \\
\hline
\end{tabular}

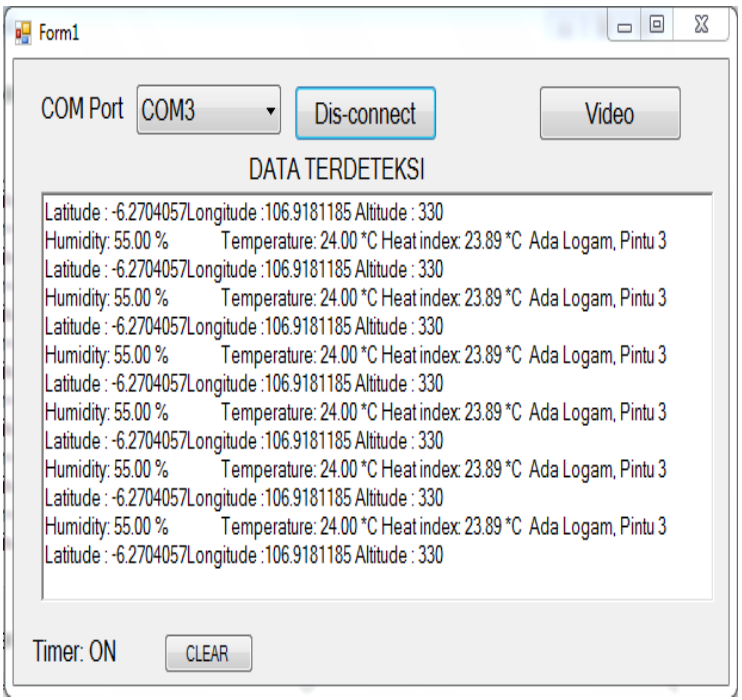

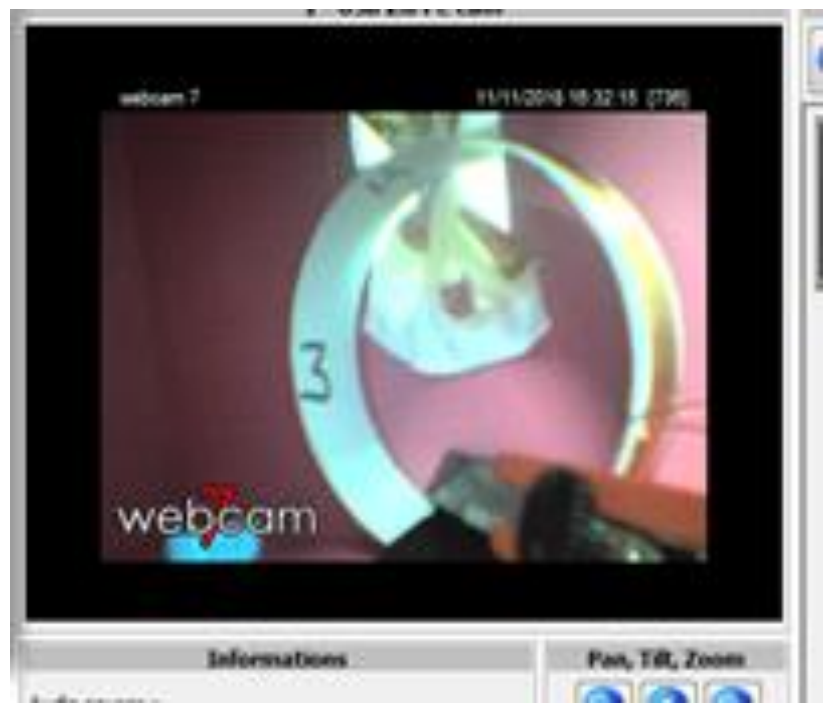

Gambar 4 Hasil tampilan sensor dan CCTVpada Prototype

\section{Analisis Instrumen Penelitian}

Instrumen non-tes berfungsi untuk mengetahui tingkat kelayakan media pembelajaran dan materi pembelajaran. Pengujian validitas instrument non-tes dilakukan dengan cara pengujian validitas isi, validitas konstruk dan validitas item. Pengujian validitas isi dan validitas konstruk dilakukan dengan cara meminta pendapat dari expert judgement. Pengujian validitas item dilakukan dengan uji coba instrument terhadap 10 orang responden, kemudian menghitung korelasi antar item. Penelitian ini instrument non-tes memerlukan uji validitas item, karena akan digunakan untuk peneletian yang menggunakan tolak ukur yang valid. Instrumen media pembelajaran memiliki 22 butir soal dan instrument materi pembelajaran memiliki 18 butir soal. Kemudian t-hitung dibandingkan dengan t-tabel. Jika t-hitung > t-tabel butir soal dikatakan valid, tetapi jika t-hitung < t-tabel, butir soal dikatakan tidak valid. t-tabel 
menggunakan tingkat signifikansi $5 \%$. Berdasarkan perhitungan t-tabel didapat 1,86. Dengan hipotesis t-hit > t-tab dianggap valid. Langkah selanjutnya adalah uji reliabilitas instrumen yaitu dilakukan dengan teknik belah dua dengan menggunakan rumus Spearman Brown. Butir-butir instrumen di belah menjadi dua buah kelompok, yaitu kelompok instrumen ganjil dan kelompok instrumen genap. Selanjutnya skor data tiap kelompok itu di jumlahkan dan dicari korelasinya. Hasil yang didapatkan reliabilitas instrumen media pembelajaran $=0,938$ dan reliabilitas instrument materi pembelajaran $=0,92$. Karena berdasarkan pengujian instrumen ini sudah valid dan realibel, maka instrument dapat digunakan untuk pengukuran dalam rangka pengumpulan data.

Selanjutnya diuji Instrument tes untuk mengukur tingkat penguasaan materi oleh responden setelah melakukan pembelajaran dengan menggunakan pretes dan postes. Pengujian validitas instrumen tes dilakukan dengan cara pengujian validitas isi dan validitas konstruk. Instrumen tes diperbaiki dan dinyatakan layak oleh expert judgement, kemudian instrumen diuji cobakan terhadap 10 responden. Kemudian hasil uji coba intrumen tes dianalisis untuk mencari tingkat reliabilitas instrument. Hasil uji reliabilitas instrument tes didapatkan reliabilitas instrumen pretes $=0,856$ dan reliabilitas instrumen postes $=0,953$. Pengujian instrumen ini sudah valid dan realibel, maka instrumen dapat digunakan untuk pengukuran dalam rangka pengumpulan data.

\section{Evaluasi Produk}

Uji coba produk dilakukan dengan tujuan untuk mendapatkan informasi, saran, kritik atau masukan yang akan digunakan untuk memperbaiki kualitas produk yang dikembangkan. Hasil tersebut dianalisis dari uji Aspek Kemanfaatan, Aspek Rekayasa Perangkat Keras dan Perangkat Lunak, Aspek Komunikasi Visual, Aspek relevansi materi, Aspek teknis media pembelajaran 

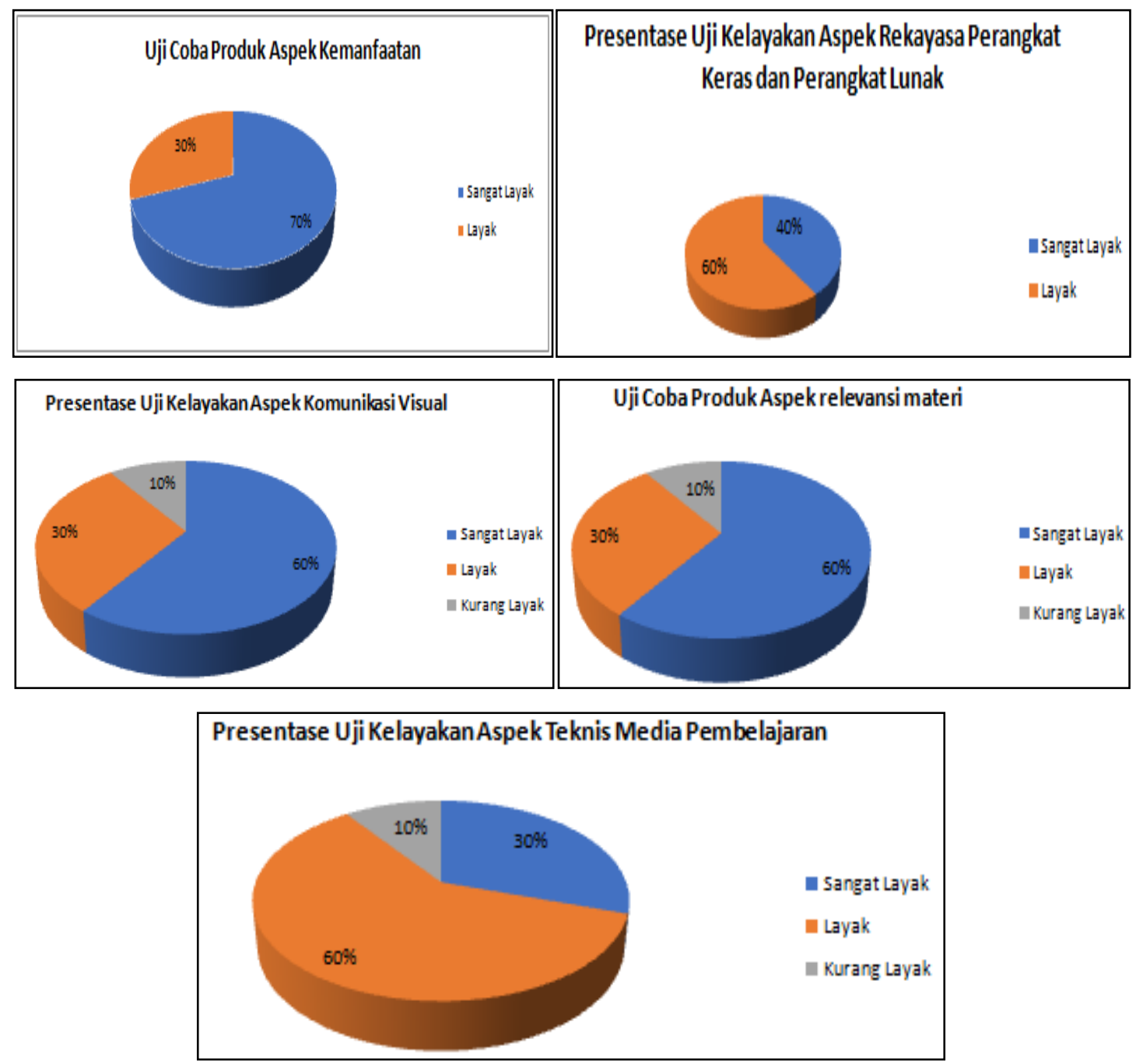

Gambar 5. Hasil Evaluasi Produk

Kegiatan pratindakan dilaksanakan melalui observasi kelas dan dialog dengan pengajar tentang beberapa permasalahan yang dihadapi dalam pembelajaran sensor keamanan, terutama pada materi sensor keamanan. Berdasarkan hasil pengamatan tersebut, maka peneliti dan tenaga pengajar Sensor keamanan sepakat untuk melaksanakan penelitian tindakan kelas (Classrom Action Research), dengan menggunakan Sensor keamanan objek dengan menggunakan sensor kamera sebagai media pembelajaran Sensor keamanan.

\section{Uji Coba Produk Dikelas}

Analisis data dalam penelitian ini adalah analisis deskripsi dari data nilai pretes dan nilai postes. Data berupa nilai pretes dan postes seperti pada tabel dirubah menjadi data interval seperti pada tabel berikut:

Tabel 2. Peningkatan Hasil Belajar Peserta Didik

\begin{tabular}{lrr}
\hline Kriteria & \multicolumn{1}{c}{ Pretes } & \multicolumn{1}{l}{ Postes } \\
\hline lulus sangat baik & $0.00 \%$ & $39.29 \%$ \\
\hline lulus baik & $3.57 \%$ & $46.43 \%$ \\
\hline Lulus & $21.43 \%$ & $14.29 \%$ \\
\hline kurang dari lulus & $32.14 \%$ & $0.00 \%$ \\
\hline Tidak lulus & $42.86 \%$ & $0.00 \%$ \\
\hline
\end{tabular}




\begin{tabular}{lrr}
\hline $\begin{array}{l}\text { Jumlah peserta } \\
\text { didik yang belajar }\end{array}$ & $\mathbf{1}$ & $\mathbf{2 4}$ \\
tuntas & & \\
\hline Nilai rata-rata & 52.62 & 74.64 \\
\hline Persentase & $3.57 \%$ & $85.71 \%$ \\
kelulusan & & \\
\hline $\begin{array}{l}\text { Jumlah } \\
\text { keseluruhan } \\
\text { peserta didik }\end{array}$ & $\mathbf{2 8}$ & $\mathbf{2 8}$ \\
& & \\
\end{tabular}

Tabel diatas menunjukan bahwa, sebelum dilakukan pembelajaran menggunakan media Sensor keamanan objek, nilai rata-rata peserta didik adalah 52,62. Pembelajaran menggunakan media berupa Sensor keamanan objek dapat meningkatkan prestasi peserta didik dengan nilai rata-rata menjadi 74,66 . Hal ini berarti terdapat peningkatan nilai rata-rata sebesar 22,06. Pembelajaran menggunakan media pembelajarn Sensor keamanan objek dengan sensor kamera dapat meningkatkan prestasi peserta didik sebesar $82,514 \%$.

\section{KESIMPULAN}

Berdasarkan data hasil penelitian dan pembahasan yang telah diuraikan di atas, maka dapat diambil kesimpulan sensor mampu mendeteksi suatu objek selama objek berada dalam jangkauan. Sensor mengenali objek berdasarkan suhu, jenis logam, dan dikirmkan langssung via GPS dan kamera. Tingkat kelayakan media pembelajaran berupa Sensor keamanan obyek dengan sensor kamera yang telah diberikan responden dinyatakan layak, dengan presentase rata-rata adalah $78,2 \%$. Penggunaan media pembelajaran Sensor keamanan obyek dengan sensor kamera dapat meningkatkan prestasi peserta didik dengan presentase rata-rata sebesar $82,514 \%$.

\section{DAFTAR PUSTAKA}

Asyhar, R. 2011. Kreatif Mengembangkan Media Pembelajaran. Jakarta: Gaung Persada (GP) Press Jakarta.

Andrianto, Heri. 2011, Menggambar TeknikRangkaian PCB, Modula, Bandung.

Azyumardi, Azra. 2012 Islam Politk Radikal di Indonesia : Akar Ideologi Terorisme, Makalah disampaikan pada Diskusi Kajian tentang Terorisme di Ditjenstrahan Kemhan tangal 16 Januari 2012. 14-15.

Bibby,J dan Necessary, R., 2008, Hands, http://robonaut.jsc.nasa.gov/R1/sub/han ds.asp, diakses pada 20 Mei 2016.

Erickson, Robert W. (1999). Fundamentals of Power Electronics.Colorao: University of Colorado.

Fadillah, Fitra. (2014). Perancangan dan Realisasi Konverter DC-DC Tipe Boost Berbasis Mikrokontroller ATMEGA8535. Bandung: Institut teknologi nasional.

Hobri. 2009. Metodologi Penelitian dan Pengembangan (Dvelopmental Research) (Aplikasi pada Penelitian Pendidikan Matematika). Jember: FKIP Universitas Jember.

Irhamna dan Widyo N. 2009. Pengembangan Bahan Ajar Berbasis Multimedia Interaktif Mata Kuliah Komputerisasi Akuntansi. Universitas Gunadarma.

Marian K. Kazimierczuk. (2008). Pulse-widht Modulated DC-DC Converter. Ohio,USA: Wright State University Dayton.

Muis, Saludin 2013, Prinsip Kerja LCD dan Pembuatannya (Liquid Crystal Display), Graha Ilmu, Yogyakarta.

Nasir, Abas. 2012. Kajian tentang Terorisme, Makalah disampaikan pada Diskusi Kajian tantang Terorisme di Ditjenstarahan Kemhan tangal 16 Januari 2012. 1.

Petruzella, Frank D., 2001.Elektronik Industri, Yogyakarta : ANDI.

Proakis, J.G, Manolakis,D.G, 1997, "Pemrosesan Sinyal Digital Jilid I", Jakarta : PT. Prenhallindo. 
Rashid, Muhammad H. (1993).Power Electronics Circuit Device and Applications. Fort Wayne Indiana: Purdue University.

Sarwiko, Dwi. 2006. Pengembangan Media Pembelajaran Berbasis Multimedia Interaktif Menggunakan Multimedia Director Mx. Jakarta: Universitas Gunadharma.

Setiawan, Iwan . 2009. Buku Ajar Sensor dan Transduser. In: Sensor dan Transduser. Faculty of Engineering, Diponegoro University, http://eprints.undip.ac.id/). diakses pada 20 Mei 2016.

Sutopo. 2012. Teknologi dan Informasi dalam Pendidikan. Yogyakarta: Graha Ilmu.

Veronica, M dan Utari., D. W. 2014, Rancang Bangun Jari Tangan Robot Pengikut Pergerakan Jari Tangan Manusia, skripsi, STMIK GI MDP.

Williams, B.W. (1992). Power Electronics (Devices, Driver, Applications and Passive Components). Edinburgh: Department of Electrical and Electronic Engineering Heriot-Watt University. 